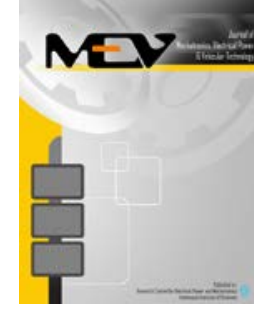

Journal of Mechatronics, Electrical Power, and Vehicular Technology

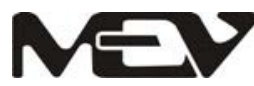

\title{
Optimization of ozone chamber using pulse width modulation for sterilization and preservation on fruits and vegetables
}

\author{
Adi Waskito ${ }^{\text {a, * }}$, Rendra Dwi Firmansyah ${ }^{\text {a }}$, Djohar Syamsi ${ }^{\text {a }}$, \\ Catur Hilman Adritya Haryo Bhakti Baskoro ${ }^{\mathrm{b}}$, \\ Anisya Lisdiana ${ }^{\mathrm{c}}$, Herkuswyna Isnaniyah Wahab ${ }^{\mathrm{c}}$ \\ ${ }^{a}$ Technical Implementation Unit for Instrumentation Development, Indonesian Institute of Sciences (LIPI) \\ Komplek LIPI JI. Sangkuriang, Building 30, Bandung 40135, Indonesia \\ ${ }^{b}$ Research Centre for Electrical Power and Mechatronics, Indonesian Institute of Sciences (LIPI) \\ Komplek LIPI Jl. Sangkuriang, Building 20, Bandung 40135, Indonesia \\ ${ }^{c}$ Research Centre for Geotechnology, Indonesian Institute of Sciences (LIPI) \\ Komplek LIPI JI. Sangkuriang, Building 70, Bandung 40135, Indonesia
}

Received 3 November 2020; Accepted 17 November 2020; Published online 22 December 2020

\begin{abstract}
Ozonizer is a method used for sterilization and food preservation by utilizing ozone produced from plasma discharge. The effective way of obtaining ozone is to use dielectric barrier discharge (DBD) plasma. The manufacture of a controlled ozonizer chamber system is important to result in effective and efficient performance. The aim of this study is to design and optimize the ozone chamber parameter using pulse width modulation (PWM). The system design is added with the Arduino Mega 2560 microcontroller and the L296N motor driver as an ozone generator radiation controller by changing the pulse width modulation to determine the ozone levels produced. The experimental results show that the ozone concentration increases by $50 \%$ on average with increasing variations of the $10 \%$ duty cycle (PWM) and the ignition time length. The optimum value is achieved on a $70 \%$ duty cycle for 60 - 300 seconds, where the ozone level of $3 \mathrm{ppm}$ is obtained and sustained for fruits/vegetables sterilization and preservation application.
\end{abstract}

(C2020 Research Center for Electrical Power and Mechatronics - Indonesian Institute of Sciences. This is an open access article under the CC BY-NC-SA license (https://creativecommons.org/licenses/by-nc-sa/4.0/).

Keywords: dielectric barrier discharge; ozone chamber; pulse width modulation; sterilization and preservation.

\section{Introduction}

Ozone gas $\left(\mathrm{O}_{3}\right)$ is a strong oxidizing agent used in many sector applications such as medical and pharmaceutical, agriculture, food industry, water purification, waste treatment, and other industrialenvironmental management. The common method used for ozone generation in industrial area uses the dielectric barrier discharge (DBD), consisting of two parallel electrodes connected to an AC power supply separated by layers of dielectric material. The method principle is a voltage applied between the two electrodes to ionize the oxygen-containing gas to form ozone. The generating ozone is based on spreading oxygen molecules with control of suitable voltage and frequency [1][2][3]. The DBD chamber is

\footnotetext{
* Corresponding Author. Tel: +62-22-2503053

E-mail address: adiw002@lipi.go.id; otiksawida@gmail.com
}

subjected to a voltage across the electrodes. The energy is supplied for the micro discharges, where oxygen molecules break into a single atom and combine with other oxygen molecules to form ozone. The advantage of using a lower applied voltage is the opportunity to have ozone generators using nonconventional dielectric materials that have much lower dielectric breakdown voltage, such as mica, alumina ceramic, thin enamel, and polymer layers materials [4].

Ozone production using DBD is affected by several factors such as voltage, electrical characteristics, flow rate, power supply and consumption, power modulation, and pulse polarity. The discharge conditions, such as gap-width, electrode material and surface, and applied voltage waveform, affect the system efficiency. The employment of pulse waveform as the applied voltage is expected to emphasize the highly 


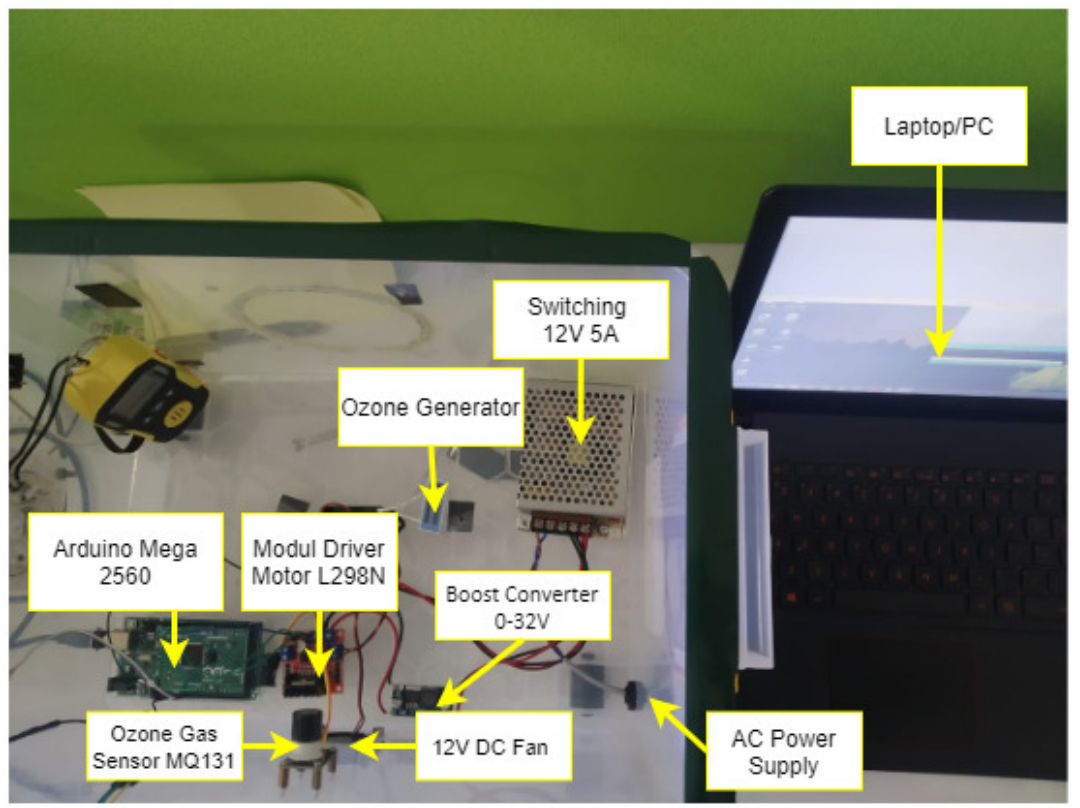

Figure 1. Design of the sterilization and preservation chamber

distorted high electric field and reduce the loss in the dielectric barrier [5][6]. The ozone production by pulsed electric fields is preferred due to shorter processing times that lead to considerable saving cost, leaves no hazardous residues, and less thermal side effects. No heat requires and hence saves energy. High voltage pulse generation can increase efficiency on the ozone generator. The switch in the pulse generator circuits only turned on typically in less than $10 \%$ of a period, which is called the duty cycle. It can be off for the rest of the time, reducing energy consumption and limiting the electrode system's heating [7]. The duty cycle variation is a simple tool to develop a practical ozone generator with widely adjustable ozone concentration and simultaneously constant ozone yield [8][9].

The food processing industry continuously improves food quality and safety, mainly related to microbial food safety concerns. Hence, various food sterilization and preservation methods to prevent microbial contamination and maintain food product quality have been evaluated. Ozone is a suitable choice for food sterilization and preservation because it has strong oxidative characteristics that make it an effective anti-microbial agent [10][11][12]. It destroys different types of microorganisms at relatively low concentrations. Ozone can rapidly be decomposed and can oxidize organic substances into safer elements, leaving no hazardous compounds in the food products. The use of ozone is an energy-saving model as the energy input required for ozone treatment is lower than other treatments, such as thermal, radiation, and microwave. Ozone could be generated on-site using ozone generators with oxygen as the gas source. Therefore it meets the global demand for sustainability. Some combination application of ozonation with other methods, i.e., pasteurization, freezing, high-pressure processing, UV, or membrane technology can be very effective in microbial inhibition and shelf life extension of food products [13][14][15]. Combination treatments of ozone, chlorine dioxide, and ultrasound could be used for strawberry preservation to prolong the shelf life. It was found more beneficial for quality factors, such as $\mathrm{pH}$, total soluble solids, texture, sugar content, and water content [16]. Ozone and UV - C disinfection methods for tomatoes, carrots, and lettuces were evaluated and found effective for the inactivation of $E$. coli. The effectiveness of such methods was influenced by the dose of the agent, the exposure time, and the surface of the food product tested. A smooth surface allows an easier sanitization process, while it shows lower inactivation on the more porous and rough surface of the fruits/vegetables products. Color changes can be controlled by optimizing the exposure time and disinfection agent concentration [17].

In this paper, ozone is generated using DBD with a plate-type reactor, with a variation of the duty cycle of pulse width modulation and reactor time duration. The generated ozone is then collected in the box equipped with an ozone meter sensor to determine its concentration. The optimization was performed to obtain the targeted ozone level. For further study, the ozone generation system's optimum condition will be used for fruits/vegetables sterilization and preservation applications, i.e., pears, apples, berries, lettuces, and onions.

\section{Materials and Methods}

The ozone room system in the experiment was carried out in a closed box measuring $60 \mathrm{~cm}$ x $40 \mathrm{~cm}$ $\mathrm{x} 40 \mathrm{~cm}$ to produce optimal work without any external disturbance factors such as wind and ambient temperature (Figure 1). The first experiment measured the maximum ozone level produced by a commercial ozone generator with the rate of change levels and the ozone's residence time in the chamber. The second experiment measures the amount of ozone produced over time changes determined using the pulse width modulation method (PWM). Finally, the third experiment 


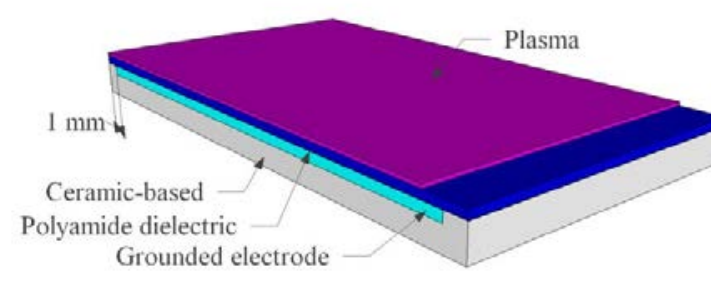

Figure 2. Dielectric barrier discharge plasma actuator

measures the length of time required for the amount of ozone determined changes in pulse width modulation.

\section{A. Sterilization and preservation chamber}

There are several methods of sterilization and preservation of foodstuffs. One of those is called an ozonation. Ozone can be formed through the collision process produced by the dielectric barrier discharge (DBD) plasma reactor, as shown in Figure 2. Oxygen molecules undergo ionization, which is the process of releasing an atom or molecules from their bonds to oxygen ions, called the plasma condition.

The ozone molecule is formed by the ionization process of oxygen gas [18]. Oxygen is oxidized by colliding with an electron ( $\left.\mathrm{e}^{-}\right)$. Furthermore, oxygen reacts with atoms $\mathrm{O}$ and $\mathrm{M}$ in the particulate form where $\mathrm{M}$ is any non reactive species that can take up the energy release in reaction to stabilize $\mathrm{O}_{3}$. $\mathrm{M}$ is either $\mathrm{O}_{2}$ or $\mathrm{N}_{2}$ which are the major components in the atmosphere.

$\mathrm{O}_{2}+\mathrm{e}^{-} \rightarrow \mathrm{O}^{-}+\mathrm{O}_{2}$

$\mathrm{O}^{-}+\mathrm{O}_{2} \rightarrow \mathrm{O}_{3}+\mathrm{e}^{-}$

$\mathrm{O}_{2}+\mathrm{O}^{-}+\mathrm{M} \rightarrow \mathrm{O}_{3}+\mathrm{M}$

Figure 3 shows the block diagram of the ozonizer system which is equipped with a speed converter and time controller. It is designed using an Arduino Mega 2560 microcontroller to get the desired ozone concentration. The ozone generator consists of an ozone reactor, a high voltage generator (HV), a fan to suck air from outside into the chamber, and a cooling medium for the ozone reactor. Sterilization and preservation system equipment is divided into three parts, namely the ozone generator to produce ozone gas, the PWM controller to control the pulse width of the ozone generator, and the chamber as the object container. The commercial ozone generator is a portable ceramic powered by $12 \mathrm{~V} \mathrm{DC}$ input voltage that produces $2.5 \mathrm{kV}$ AC output voltage, $450 \mathrm{~mA}$ working current, $6 \mathrm{~W}$ power, and $200 \mathrm{mg} / \mathrm{h}$ ozone output. The L296N motor driver module controls the ozone generator converter, boost converter $(0-32 \mathrm{~V})$ to change the output voltage by $14 \mathrm{~V}$ required by the motor driver module, gas ozone sensor, and a 12 V 5 A switching.

\section{B. Ozone gas sensor}

In this experiment, a semiconductor gas sensor (MQ-131) that can read the range of $10-1000 \mathrm{ppm}$ is used to measure the ozone gas concentration. This sensor work system requires an input voltage of $5 \mathrm{~V}$ DC and a heating time of 48 hours before use to get the sensitivity of the response to the correct reading and is calibrated with an ozone meter (BH-90A) to ensure that the reading is accurate along with any changes in the levels of ozone gas produced.

\section{Pulse width modulation (PWM)}

The modulation technique is applied by changing the pulse width (Duty Cycle) with a fixed amplitude and frequency. This experiment uses Arduino Mega 2560 as an L296N motor driver of a pulse width control module to control the ozone generator radiation to determine the amount of ozone concentration produced. This study used a randomized block design in taking the sample data to characterize the chamber design; each treatment combination was repeated three times. The treatment control consists of adjusting the pulse width of $10 \%-100 \%$ with the duration of the ozone generator is varied from 60 to 300 seconds. The time rate results are obtained with the variation of the ozone concentration is set at $1-3 \mathrm{ppm}$.

\section{Results and Discussions}

The experiment was done to determine the maximum working capacity of the ozone generator for 30 minutes. Figure 4 shows that within 20 minutes of observation, the optimal value is obtained after 9 minutes. There is no change in the ozone level produced in the remaining observation time. Initially, the ozone produced reaches the

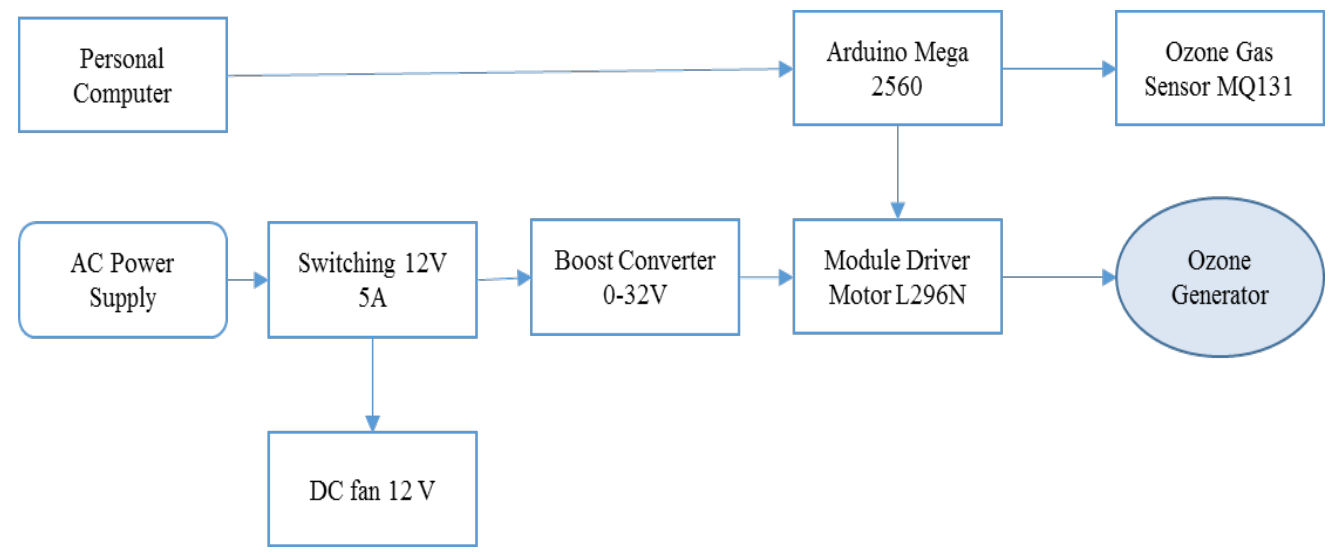

Figure 3. Block diagram of the ozonizer system 


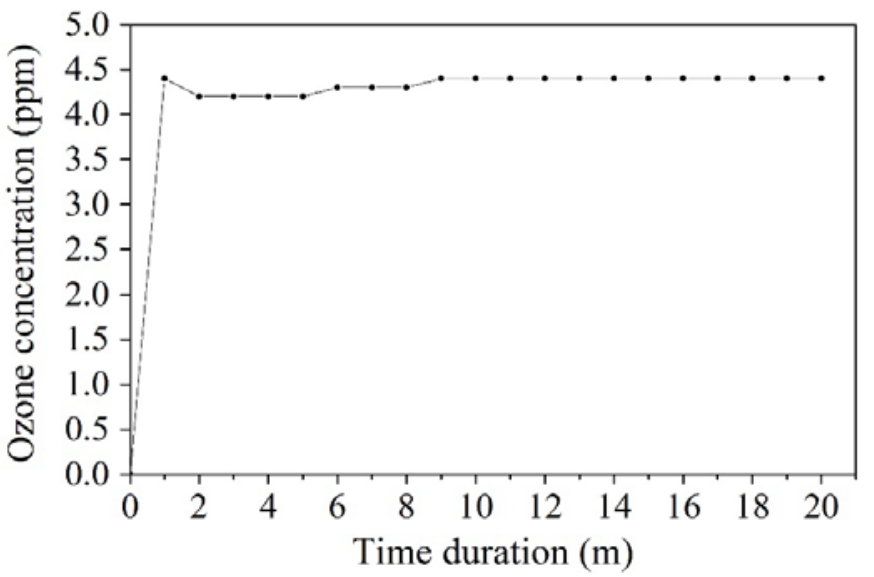

Figure 4. Plot of the ozone generator performance

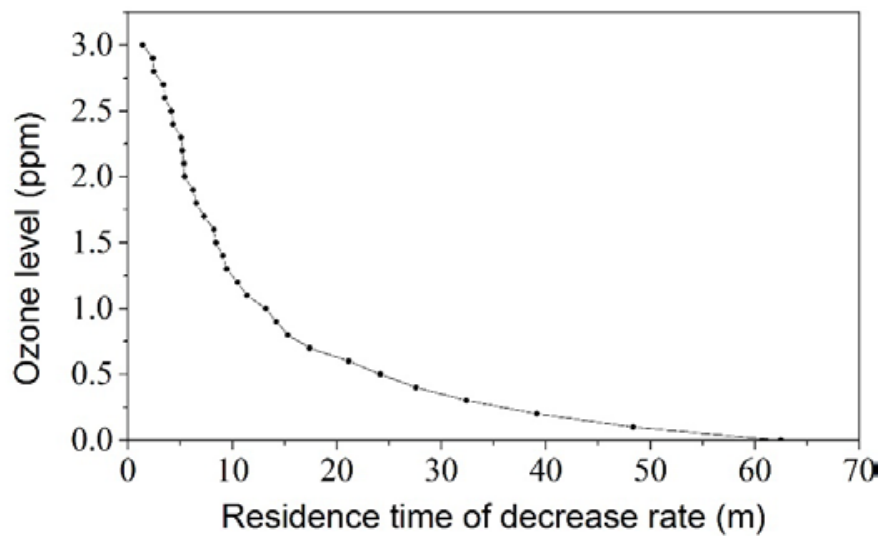

Figure 5. Plot of ozone residence time and decline rate in the chamber
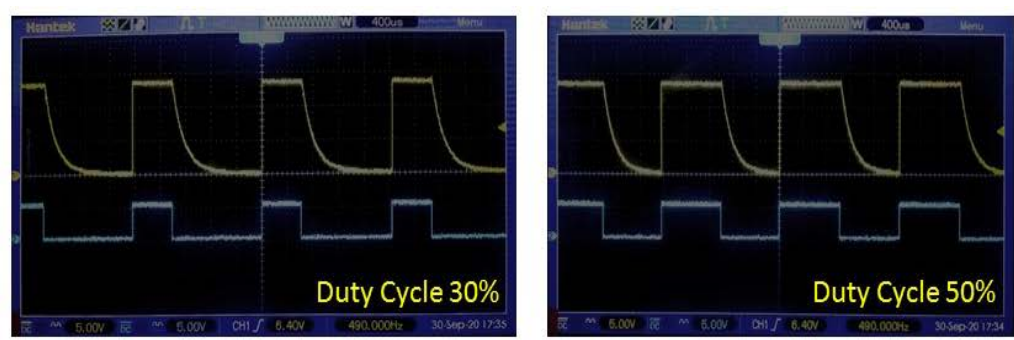

Figure 6. PWM signal graph

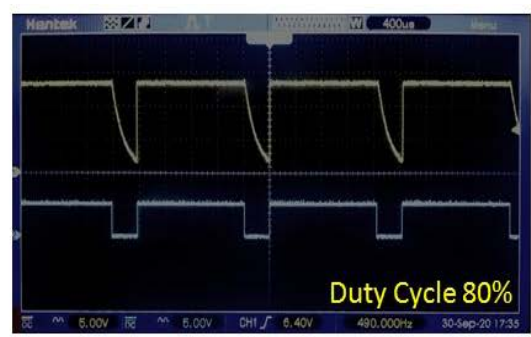

residue and improving the storage quality of tomato [20]. The duration from the ozone stayed until lost in the chamber for 3 ppm concentration is 62 minutes 28 seconds. Meanwhile, the time to maintain a 3 ppm level is only 2 minutes 4 seconds after the concentration rate decreases until it disappears.

The amount of ozone concentration was controlled using Pulse Width Modulation (PWM). Figure 6 shows a graph of the PWM duty cycle of $10 \%, 50 \%, 80 \%$, with the motor driver voltage of 14 volts, where the voltage per division is 5 volts. The results obtained from the oscilloscope observation show that the PWM signal control is appropriate based on the voltage graph according to the amount of the duty cycle used.

The PWM control with a change in the duty cycle of $10 \%-100 \%$ for 60 to 300 seconds was shown in Figure 7. It can be seen from the graph that the higher the percentage of the duty cycle used, the ozone levels and the efficiency value of the PWM percent control increase. The optimum of the duty 

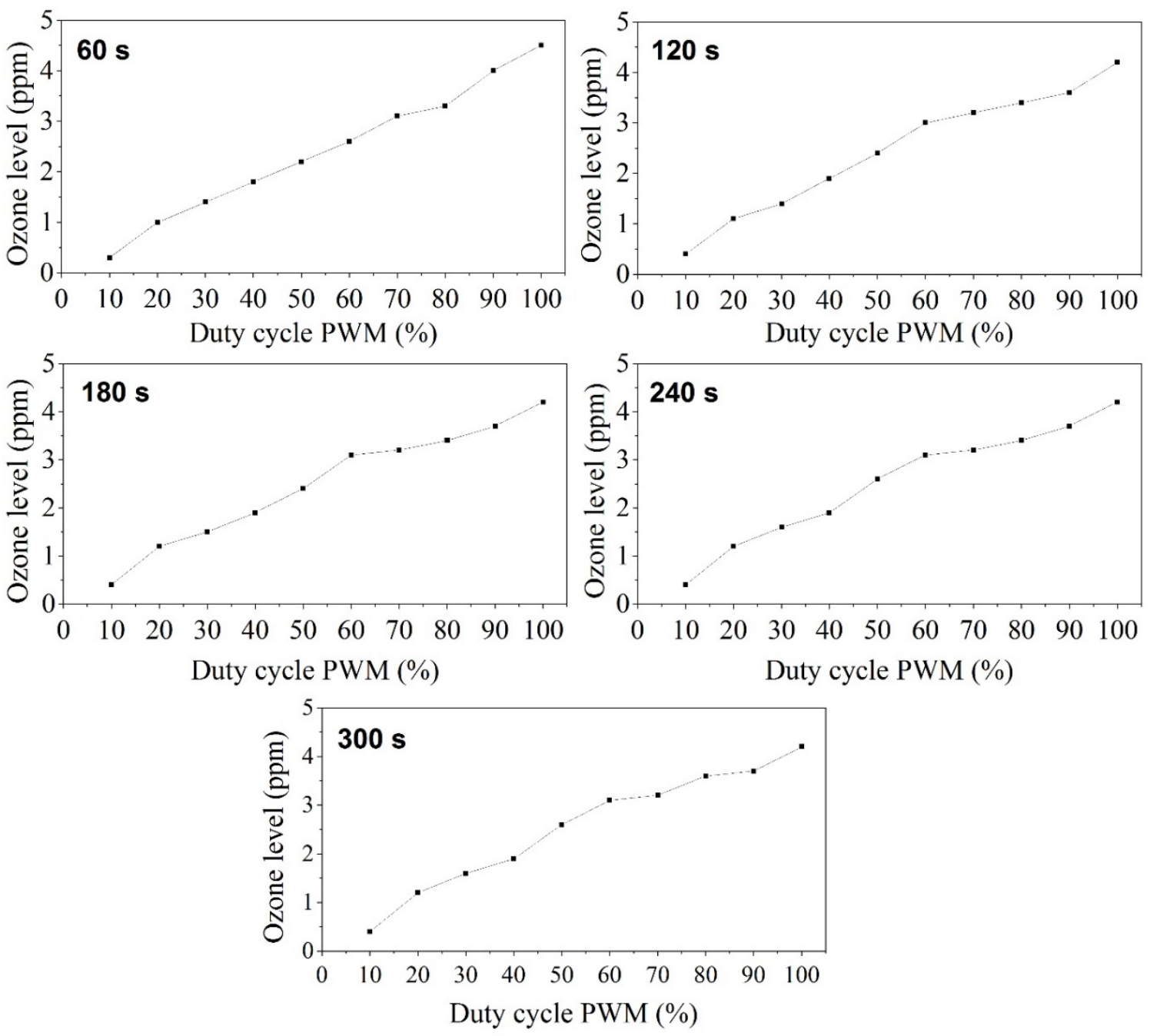

Figure 7. Graph of ozone production based on duty cycle and time

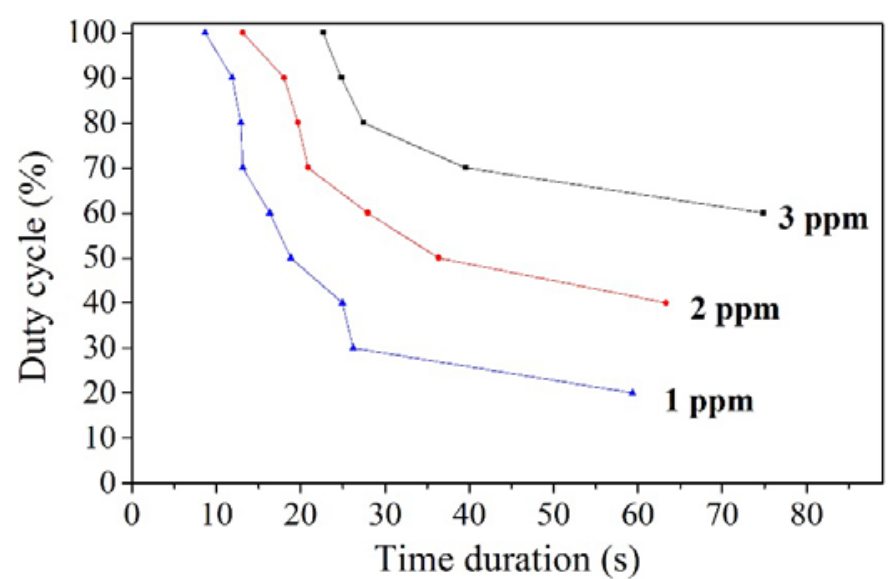

Figure 8. Graph of the ozone time requirements

cycle was found at $70 \%$, where the ozone level of 3 ppm is obtained and sustained. In observations during the experiment on the length of the ignition time with a duty cycle of $10 \%-80 \%$, the ozone level experienced an increased rate when showing the ignition time of 60 - 120 seconds, while when entering the ignition time of 130 - 300 seconds, the ozone level obtained was constant. However, when the duty cycle treatment is $90 \%-100 \%$, the ozone levels fluctuate, wherein the initial 60 seconds the rate increases, then at 100 - 300 seconds, the rate decreases until it becomes constant. It is most likely influenced by the characteristics of the ozone generator used.

The duration to reach a predetermined ozone level was measured with ozone level variation 1 - 3 ppm. Figure 8 shows that the greater the percentage of duty cycle used, the faster the time required to reach the predetermined ozone level. It was also revealed that when the ozone generator's set-point was set to $1 \mathrm{ppm}$, the $10 \%$ duty cycle was unable to reach the set-point value even with infinite ignition 
time. Furthermore, when the set-point is increased by 2 ppm, the duty cycle of $10 \%-30 \%$ is unable to achieve it. Then, when it is increased by $3 \mathrm{ppm}$, the duty cycle of $10 \%-50 \%$ could not achieve it. It can be concluded that the greater the specified ozone level, the smaller range of the duty cycle allowed.

\section{Conclusion}

The ozonizer chamber is designed based on pulse width modulation using a high voltage DC ozone generator. Optimization of the ozone chamber system was performed to obtain an effective and efficient performance. The experimental results show that increasing $10 \%$ duty cycle variation affects the generated ozone concentration by $50 \%$ on average. The optimum value was achieved on a $70 \%$ duty cycle for 60 - 300 seconds, where 3 ppm ozone level is obtained and sustained for fruits/vegetables sterilization and preservation applications.

\section{Acknowledgement}

This work was supported by the National Priority program, Deputy of Scientific Services, Indonesian Institute of Sciences.

\section{Declarations}

\section{Author contribution}

All authors contributed correspondingly as the main contributor to this paper. All authors read and endorsed the final paper.

\section{Funding statement}

This research did not receive any particular grant from funding agencies in the public, commercial, or not-forprofit sectors.

\section{Conflict of interest}

The authors declare no conflict of interest.

\section{Additional information}

No additional information is available for this paper.

\section{References}

[1] Y. Chen and Z. Wang, "Soft-switched technology for ozone generator based on capacitive phase shift control," Proc. 2019 IEEE 3rd Adv. Inf. Manag. Commun. Electron. Autom. Control Conf. IMCEC 2019, pp. 219-222, 2019.

[2] S. Ketkaew, "Development of Corona ozonizer using high voltage controlling of produce Ozone gas for cleaning in cage," Mod. Environ. Sci. Eng., vol. 3, no. 7, pp. 505-509, 2017.

[3] M. Ponce-Silva, J. A. Aqui, V. H. Olivares-Peregrino, and M. A Oliver-Salazar, "Assessment of the Current-Source, Full-Bridge Inverter as Power Supply for ozone Generators with High Power Factor in a Single Stage," IEEE Trans, Power Electron., vol. 31, no. 12, pp. 8195-8204, 2016.
[4] M. Facta, Hermawan, Karnoto, Z. Salam, and Z. Buntat, "Double dielectric barrier discharge chamber for ozone generation," 2014 1st Int. Conf. Inf. Technol. Comput. Electr. Eng. Green Technol. Its Appl. a Better Futur. ICITACEE 2014 - Proc., vol. I, pp. 409-412, 2015

[5] T. Miura, T. Sato, K. Arima, S. Mukaigawa, K. Takaki, and T. Fujiwara, "Duty factor effect on ozone production using dielectric barrier discharge reactor driven by IGBT pulse modulator," J. Adv. Oxid. Technol., vol. 10, no. 2, pp. 311-315, 2007.

[6] E. Yulianto et al., "Effect of duty cycle on ozone production using DBDP cylindrical reactor," J. Phys. Conf. Ser., vol. 1217, no. $1,2019$.

[7] P. P. Abkenar, H. Iman-Eini, M. H. Samimi, and M. Emaneini, "Design and implementation of ozone production power supply for the application of microbial purification of water," IEEE Trans. Power Electron., vol. 35, no. 8, pp. 8215-8223, 2020.

[8] R. Barni, I. Biganzoli, E. C. Dell' Orto, and C. Riccardi, "Effect of duty-cycles on the air plasma gas-phase of dielectric barrier discharges," J. Appl. Phys., vol. 118, no. 14, p. 143301, 2015.

[9] Y. F. Zhang, L. S. Wei, X. Liang, H. Z. Deng, and M. Šimek, "Characteristics of the discharge and ozone generation in Oxygen-Fed coaxial DBD using an amplitude-modulated AC power supply," Plasma Chem. Plasma Process., vol. 38, no. 6, pp. 1199-1208, 2018.

[10] T. Bhilwadikar, S. Pounraj, S. Manivannan, N. K. Rastogi, and P. S. Negi, "Decontamination of microorganisms and pesticides from fresh fruits and vegetables: a comprehensive review from common household processes to modern techniques," Compr. Rev. Food Sci. Food Saf., vol. 18, pp. 1003-1038, 2019.

[11] M. Glowacz and D. Rees, "The Practicality of Using ozone with Fruit and Vegetables," J. Sci. Food Agric., vol. 96, no. 14, pp. 4637-4643, 2016.

[12] M. Aziz and S. Karboune, "Natural Antimicrobial/Antioxidant Agents in Meat and Poultry Products as Well as Fruits and Vegetables: A Review," Crit. Rev. Food Sci. Nutr., vol. 58, no. 3, pp. 486-511, 2018.

[13] R. Pandiselvam, S. Subhashini, E. P. Banuu Priya, A. Kothakota, S. V. Ramesh, and S. Shahir, "Ozone based food preservation: a promising green technology for enhanced food safety," Ozone Sci. Eng., vol. 41, no. 1, pp. 17-34, 2019.

[14] H. Nakamura, M. Oya, T. Hanamoto, and D. Nagashio, "Reviewing the 20 years of operation of Ozonation facilities in Hanshin water supply authority with respect to water quality improvements," ozone Sci. Eng., vol. 39, no. 6, pp. 397-406, 2017.

[15] M. A. Khadre, A. E. Yousef, and J. G. Kim, "Microbiological aspects of ozone applications in food: a review," J. Food Sci., vol. 66, no. 9, pp. 1242-1252, 2001.

[16] M. S. Aday and C. Caner, Individual and combined effects of ultrasound, ozone and Chlorine Dioxide on strawberry storage life, vol. 57, no. 1. Elsevier Ltd, 2014.

[17] D. Bermúdez-Aguirre and G. V. Barbosa-Cánovas, "Disinfection of Selected Vegetables Under Nonthermal Treatments: Chlorine, Acid Citric, Ultraviolet Light and ozone," Food Control, vol. 29, no. 1, pp. 82-90, 2013.

[18] D. N. Meivita, M. Rivai, and A. N. Irfansyah, "Development of an electrostatic air filtration system using fuzzy logic control," Int. J. Adv. Sci. Eng. Inf. Technol., vol. 8, no. 4, pp. 1284-1289, 2018.

[19] S. L. Rodgers, J. N. Cash, M. Siddiq, and E. T. Ryser, "A comparison of different chemical sanitizers for inactivating Escherichia coli 0157:H7 and Listeria Monocytogenes in solution and on apples, lettuce, strawberries, and cantaloupe," J. Food Prot., vol. 67, no. 4, pp. 721-731, 2004.

[20] A. A. Z. Rodrigues et al., "Use of ozone and detergent for removal of pesticides and improving storage quality of tomato," Food Res. Int., vol. 125, p. 108626, 2019 